\title{
Ethnicity and health inequalities: an empirical study based on the 2010 China survey of social change (CSSC) in Western China
}

\author{
Y. J. Wang ${ }^{1,2}$, X. P. Chen ${ }^{1,2,4}$, W. J. Chen ${ }^{3}$, Z. L. Zhang ${ }^{1,24^{*}}$, Y. P. Zhou ${ }^{3}$ and Z. Jia ${ }^{1}$
}

\begin{abstract}
Background: In China, ethnic minorities often live in frontier areas and have a relatively small population size, and tremendous social transitions have enlarged the gap between eastern and western China, with western China being home to 44 ethnic minority groups. These three disadvantages have health impacts. Examining ethnicity and health inequality in the context of western China is therefore essential.

Methods: This paper is based on data from the 2010 China Survey of Social Change (CSSC2010), which was conducted in 12 provinces, autonomous regions and province-level municipalities in western China and had a sample size of 10,819. We examined self-rated health and disparities in self-rated health between ethnic minorities and Han Chinese in the context of western China. Self-rated health was coded as poor or good, and ethnicity was coded as ethnic minority or Han Chinese. Ethnic differences in self-rated health was examined by using binary logistic regression. Associations among sociodemographic variables, SES variable, health behaviour variable, health problem variables and self-rated health were also explored.

Results: Fourteen percent of respondents reported their health to be poor. A total of $15.75 \%$ of ethnic minorities and $13.43 \%$ of Han Chinese respondents reported their health to be poor, indicating a difference in self-rated health between ethnic minorities and Han Chinese. Age, gender, marital status, education, alcohol, and health problems were the main factors that affected differences in self-rated health.

Conclusion: In western China, there were obvious ethnic disparities in self-rated health. Elderly ethnic minorities, non-partnered ethnic minorities, ethnic minorities with an educational level lower than middle school, and ethnic minorities with chronic disease had higher odds of poor self-rated health.
\end{abstract}

Keywords: Ethnic disparity, Self-rated health, Health inequality, Western China

\footnotetext{
* Correspondence: zhangzl@|zu.edu.cn

'College of Earth and Environmental Sciences, Lanzhou University, Lanzhou 730000, China

${ }^{2}$ Research Center for Circular Economy in Western China, Lanzhou University, Lanzhou 730000, China

Full list of author information is available at the end of the article
}

(c) The Author(s). 2020 Open Access This article is licensed under a Creative Commons Attribution 4.0 International License, which permits use, sharing, adaptation, distribution and reproduction in any medium or format, as long as you give appropriate credit to the original author(s) and the source, provide a link to the Creative Commons licence, and indicate if changes were made. The images or other third party material in this article are included in the article's Creative Commons licence, unless indicated otherwise in a credit line to the material. If material is not included in the article's Creative Commons licence and your intended use is not permitted by statutory regulation or exceeds the permitted use, you will need to obtain permission directly from the copyright holder. To view a copy of this licence, visit http://creativecommons.org/licenses/by/4.0/. The Creative Commons Public Domain Dedication waiver (http://creativecommons.org/publicdomain/zero/1.0/) applies to the data made available in this article, unless otherwise stated in a credit line to the data. 


\section{Background}

Health inequality issues have been well documented in developed countries for decades but have been relatively less reported in developing countries. There is an urgent need for studies of health inequality in developing countries, especially China, due to the goals of social stabilization and the 2030 Agenda for Sustainable Development. Health inequalities exist across different countries and regions and even among individuals. Undeniably, the health status of a population improves along with economic development and bio-tech advances; however, low-income economies still lag behind high-income economies in terms of health issues, and health inequalities even exist within high-income economies [1, 2]. In America, researchers tend to focus on race-related disparities in health, whereas European researchers prefer to elucidate the socioeconomic status and class contributions to health inequalities. In China, studies are less focused on race-related disparities in health issues.

\section{Racial disparities in health inequality}

To date, race has received extensive attention in the health geography, sociology and public health literature in relation to health inequalities, and racial disparities have been shown to exist across health outcomes [311]. However, the dispute about what race is has posed a fundamental challenge to these study findings [12-14]. W.E.B. Du Bois challenged the traditional theory of the biological interpretation of health inequalities and suggested that ethnic disparities in health inequality are based on social factors rather than natural physiological differences [15]. Link and Phelan found that social conditions are the fundamental cause of differences in disease rates; people with higher SES have lower disease risk factors than people with lower SES [16]. In China, a sizeable body of literature has documented health inequalities based on socioeconomic status and the urban/ rural divide. These study findings demonstrated that SES inequalities existed across health outcomes and that rural residents had less access to health care resources than their urban counterparts [17-24].

Although the interpretation of health inequalities based on race has generated extensive disputes, it cannot be ignored that racial inequalities in health have persisted over time worldwide despite progress in economic development and bio-tech advances. In China, the overall health status of ethnic minorities has significantly improved since the founding of the People's Republic of China (PRC) in 1949; however, continued lags in the health, mortality and life expectancy of ethnic minorities call for urgent attention. Qian explored the mortality rates of 38 ethnic minorities based on the third national census data in 1982 and found that the total mortality rate of the 38 ethnic minorities was $9.47 \%$, which was $3.11 \%$ higher than the national average level; among the 38 ethnic minorities, only the Manchu mortality rate was lower than the national average rate [25]. Chen found that the ethnic minority infant mortality rate was $50.95 \%$ in 1990 , which decreased to $46.06 \%$ o in 2000 ; notably, the De'ang, Hani, Jino, Lahu, Nu, and Va ethnic minority infant mortality rates were still more than $100 \%$ in 2000 [26].

\section{Economic factors associated with health inequality}

Health inequality among poor and disadvantaged groups is a long-standing but still current issue that has drawn extensive attention for decades. Such individuals generally experience worse health status and die earlier than wealthier or more privileged groups [27]. Health inequality occurs across different countries, regions, nationalities/ethnicities, and even individuals [28, 29]. Research on European countries and the United States has indicated that ethnic minorities generally report poorer self-rated health than ethnic majorities [30-33].

The most prominent explanation for ethnic health inequalities is the interaction between ethnicity and socioeconomic status/spatial inequalities among ethnic groups [32, 34-36] rather than genetic differences [31]. Poverty, low income, lower-status employment, and employment grade are the factors that have been most explored in relation to health inequality $[37,38]$. In particular, SES is an important indicator of health [39-42]. People with high SES often have access to a wide range of resources, such as knowledge, money, reputation, power, and social connections. All these factors have a positive impact on their health [27]. Those with low SES might have worse health status [23]. In addition, adults with low SES have higher chances of having psychological diseases, such as depression. The same trend has also been observed among children. Children from poor families have higher chances of depression than those from wealthy families [43]. The more pronounced individuals' income inequality is in their childhood, the lower their self-rated health as adults [44].

In terms of the effect of income inequality on health outcomes, a large body of literature has examined the negative effects of income inequality on population health since the 1970s [45-49]. Early researchers explored the association between health outcomes and income inequality using the Gini coefficient. However, different conceptualizations and measurements of income inequality, such as those based on absolute income, relative income, deprivation and social capital, may reflect different relations between health outcomes and income inequality.

\section{Social factors associated with health inequality}

Further, other explanations relate social network factors to health outcomes. Studies of the effects of social 
networks on health also emerged in the 1970s through the work of innovators such as Cassel, Cobb, and Berkman, who theorized or empirically demonstrated that social networks could affect mortality [50-54]. Namely, there are dyadic effects (e.g., two spouses) [55, 56], supra-dyadic effects (e.g., infectious disease or a fad) [57], and neighbourhood effects on health [58]. Schulz's research on the Detroit metropolitan area indicated that the spatial factor of residential isolation affected access to and utilization of political, economic, and social resources by African Americans, thereby affecting their political participation, employment, education, public community infrastructure and safety and ultimately affecting their health status [59] .

\section{Health inequality in China}

In China, rapid globalization, industrialization, and urbanization and the ageing of the population seen during this transition have had an enormous impact on the health and spatial distribution of health care resources across different regions and population groups, resulting in significant health inequality [60]. Residents in western China tend to have worse health than their counterparts in southeastern coastal regions [61]. Although the overall heath level of the entire country has improved, there is still a gap between wealthier and poorer provinces. For example, the life expectancies of residents of Beijing and Shanghai from 1981 to 2000 increased from 71.9 to 76.1 and from 72.9 to 78.1 years, respectively, whereas the life expectancy of residents of Gansu Province increased only by 1.4 years from 66.1 to 67.5 years [62] Studies on the population health levels in eastern, central and western China have indicated profound differences among different regions. Economic growth has exacerbated rather than mitigated these differences [63, 64]. In terms of the distribution and utilization of health care resources, the gap between urban and rural residents is also significant [18]. The unequal distribution of health care resources and low accessibility of health services worsens the health status of poor and disadvantaged groups. Resource allocation disparities between urban and rural areas embodied with China's urbanrural binary social structure have left rural residents with less access to health care resources than their urban counterparts [19, 65].

In addition, the ethnic and cultural diversity within China makes health inequalities more complicated and more intertwined with the wax and wane of the economy. Therefore, health inequalities among different ethnic groups are an issue that cannot be neglected. Ethnic minorities in China are mostly located in remote and poor regions. Ethnic minorities mainly live in remote and mountainous geographic locations, which makes their lives difficult. Poston and Shu's demographic study of 15 ethnic groups in China based on the dissimilarity index showed that the dissimilarity indexes for the educational levels of Manchu and Mongolians compared with those of Han Chinese were the smallest (i.e., the most similar to Han Chinese), whereas the dissimilarity indexes of Tibetans and Hani were the largest [66]. Based on the third and fourth national census data, Zhang studied the child health conditions of 42 ethnic minorities in China, indicating that the child mortality rate of ethnic minorities was twice the national child mortality rate [67].

Based on evidence from the literature, we found that the existing empirical studies on the health status of ethnic minorities have mostly been conducted in the fields of epidemiology, public health, psychology, sociology and human geography [68-71]. However, studies on the ethnic disparities of health inequality in western China are rare. There are two main reasons for this lack of research. First, there is a lack of data, and large-scale surveys on the health status of ethnic minorities in western China are scarce. Second, according to the sixth national census of China, ethnic minorities account for $8.4 \%$ of the total population of the People's Republic of China. Restricted by their sample sizes, most sampling surveys have not been able to provide enough valid samples, resulting in a very low proportion of ethnic minorities in the final effective samples; therefore, they could not meet the requirements for statistical inference.

The 2010 China Survey of Social Change (CSSC2010) does meet the above conditions mentioned in the last paragraph. Therefore, this study used data from CSSC2010 to examine ethnic health inequality in western China. There are 12 provinces/autonomous regions/ province-level municipalities with a total area of 6.86 million square kilometres in western China, and 44 ethnic minority groups inhabit this area. Nearly 40 years of profound social economic transitions have made the health issues of ethnic minorities much more complicated and have led to growing economic inequality between eastern and western China. The primary aim of this study was to examine ethnic differences in self-rated health, so the following hypothesis was proposed: H1, ethnic minorities' self-rated health is worse than that of Han Chinese. The secondary aim was to examine associations among sociodemographic variables, SES variables, health behaviour variables, health problem variables and self-rated health. Based on the literature described above, this study proposed the following hypotheses, as shown in Table 1.

\section{Methods}

Data

We drew on data from the 2010 China Survey of Social Change (CSSC2010), a project hosted by Xi'AN Jiaotong 
Table 1 List of Hypotheses

\begin{tabular}{|c|c|c|}
\hline Primary hypothesis & $\mathrm{H} 1$ & Ethnic minorities' self-rated health is worse than that of Han Chinese \\
\hline \multirow{9}{*}{$\begin{array}{l}\text { Secondary } \\
\text { hypotheses }\end{array}$} & $\mathrm{H} 2$ & Older people are more likely than younger people to report poor self-rated health \\
\hline & $\mathrm{H} 3$ & Women are more likely than men to report poor self-rated health \\
\hline & $\mathrm{H} 4$ & Non-partnered people are more likely than partnered people to report poor self-rated health \\
\hline & H5 & $\begin{array}{l}\text { People with higher education levels are more likely than those with lower education levels to report good self-rated } \\
\text { health }\end{array}$ \\
\hline & $\mathrm{H} 6$ & $\begin{array}{l}\text { People with high subjective social status are more likely than those with low subjective social status to report good self- } \\
\text { rated health }\end{array}$ \\
\hline & $\mathrm{H} 7$ & Non-smokers are more likely than smokers to report good self-rated health \\
\hline & $\mathrm{H} 8$ & Non-drinkers are more likely than drinkers to report good self-rated health \\
\hline & $\mathrm{H} 9$ & $\begin{array}{l}\text { People with low physical exercise frequency are more likely than those with high physical exercise frequency to report } \\
\text { poor self-rated health }\end{array}$ \\
\hline & $\mathrm{H} 10$ & People with chronic disease are more likely than those without chronic disease to report poor self-rated health \\
\hline
\end{tabular}

University in Shaanxi Province and collaboratively conducted by Lanzhou University in Gansu Province, Guangxi University for Nationalities in Guangxi Zhuang Autonomous Region, Qinghai Normal University in Qinghai Province, Southwestern University of Finance and Economics in Sichuan Province, Xinjiang University in Xinjiang Uygur Autonomous Region, Lhasa Normal College in Tibet Autonomous Region, Guizhou Minzu University in Guizhou Province, Chongqing Normal University in Chongqing Municipality, North Minzu University in Yunnan Province, Ningxia University in Ningxia Hui Autonomous Region and Inner Mongolia University in Inner Mongolia Autonomous Region. This panel survey covered 12 provinces, autonomous regions and province-level municipalities in western China.

The CSSC2010 was designed to collect data on economic development and social transformation in western China, including population and health, family and intergenerational relations, social networks, social values, religion, environmental problems and others [72]. The CSSC2010 was a cross-sectional regional representative survey that was conducted in 2010 by using probability proportional to size (PPS) sampling, with a total sample of 10,946 households living in western China (12 provinces, autonomous regions or province-level municipalities). Oral consent was obtained from respondents aged above 18 within the households to complete a self-reported questionnaire. Missing data are inevitable in practice. According to Rubin's theory [73], after listwise deletion of variables with missing information, the final sample used in this analysis consisted of 10,819 respondents of varying ethnicities residing in western China. There were 2962 ethnic minority respondents from 28 ethnic groups, namely, Tibetan, Hui, Uygur, Zhuang, Tujia, Mongolian, Dong, Yi, Miao, Buyi, Kazak, Yao, Man, Dai, Tu, Hani, Bai, Dongxiang, Alkiz, Mulao, Kelao, Li, Lahu, Shui, Naxi, Daur, Qiang, and Jing.

\section{Variables}

\section{Dependent measure}

The dependent variable, self-rated health, was measured using the responses provided in the questionnaire. Respondents were asked to answer the following question: "Would you say your health is 'very good', 'good', 'fair', 'poor' or 'very poor'?". Responses were classified into two categories: 'poor health' (poor, very poor) and 'good health' (fair, good, very good) [74, 75].

Although self-rated health is a subjective measure of health status, it is a valid predictor with good reliability $[76,77]$. Compared with many other objective measures of health, self-rated health is a robust predictor of mortality and morbidity [74, 75]. It has been widely used in studies of health research [21, 44, 73-75].

\section{Independent measures}

According to the study aims and hypotheses, independent measures were classified into two groups: independent variables for the primary study aim and independent variables for the secondary study aims.

\section{Independent variables for the primary study aim}

To the best of our knowledge, human geographic studies have seldom related ethnicity to health inequality in China. In view of this, ethnicity (Minzu) was the main explanatory variable, which was self-reported by respondents with 56 ethnic identities that have been defined in China. These ethnic divisions remained unchanged throughout the study period. Due to the small ethnic minority subsample sizes, we collapsed responses regarding ethnicity into two ethnic categories: Han Chinese and ethnic minority (the other 28 ethnicities). We recoded this measure into two categories, where $1=$ Han Chinese and $0=$ Ethnic minority. It should be noted that we collapsed the other 28 ethnic minorities into one category; thus, the results of this study are applicable to 
ethnic minorities as a whole rather than to any specific ethnicity (Minzu).

\section{Independent variables for the secondary study aims}

1. Socio-demographic characteristics Three measures were selected to examine the association between demographic characteristics and health: age, gender, and marital status. Age was included and categorized as "young", "middle aged" and "older". Marital status was categorized as "partnered" (married or de facto) and "non-partnered" (single, widowed, divorced or separated).

2. SES measures SES was mainly measured by two indicators: educational level and subjective social status (SSS). SSS refers to an individual's subjective perception of his/her social status in society. It has been widely used in health research, and a positive association exists between subjective social status (SSS) and self-rated health [21, 78, 79]. Moreover, research has already concluded that this association is not caused by common method bias [78]. SSS was measured by asking respondents, "In our society, the socioeconomic statuses of some groups are at the top, and those of some groups are at the bottom. Which level do you think reflects your socioeconomic status?" Respondents provided their responses on a scale from 1 to 5: "lower," "lower-middle," "middle," "upper-middle," and "upper." Educational level was classified into 5 groups (illiterate, primary school, middle school, senior high school or secondary technical school, and university and above).

3. Health behaviour measures Health behaviour variables were measured based on respondents' self-reported alcohol consumption, current smoking status, and physical activity. It has been widely recognized that health behaviour influences health. Non-smoking, lower-risk alcohol consumption and more physical activity have been associated with lower levels of psychological distress and improved self-rated health [80-82]. Alcohol consumption was measured based on the frequency of drinking behaviour. Respondents were classified as non-drinkers, low-risk drinkers, moderate-risk drinkers, and high-risk drinkers. Current smoking status was measured with a question asking respondents about the number of cigarettes smoked every day, and each respondent was classified as a "current smoker" or "non-smoker". Physical activity was measured by the following question: "In the last half year, did you participate in any physical activity, such as playing ball, doing Tai Chi, or practising Chinese martial arts?" Responses were categorized as regularly/ every day, several times a week, several times a month, once a month or less, and never.
4. Health problem measures The impact of chronic diseases on overall population health is growing. According to the WHO global report, $80 \%$ of chronic disease deaths occur in low- and middle-income countries, where most of the world's population lives [83]. Respondents reported their current physical condition from the chronic disease list in the questionnaire. Respondents were classified into 2 categories: person with a chronic disease and non-sufferer.

\section{Statistical analysis}

Statistical analysis was performed by using the SPSS version 20 software for Windows, with 95\% confidence intervals. Descriptive statistics were calculated, and variables related to sociodemographic aspects, socioeconomic status and health aspects (age, gender, marital status, education, subjective social status, smoking, alcohol consumption, physical exercise and chronic disease) were treated as categorical variables. All categorical variables were expressed as percentages. First, we used binary logistic regression to explore the associations between ethnicity and self-rated health. Second, for statistically significant associations between ethnicity and self-rated health, we then examined possible mediation by age, gender, marital status, education, subjective social status, smoking, alcohol consumption, physical exercise and chronic disease.

\section{Results \\ Descriptive characteristics of the sample}

Table 2 presents the descriptive characteristics of our sample. The final sample consisted of more Han Chinese (73\%; $n=7857)$ than ethnic minorities $(27 \%, n=2962)$, and the mean age of the respondents was 45.1 years $(\mathrm{SD}=$ 14.8 years; range $18-99$ years $) ; 14 \%(n=1520)$ of respondents reported their health as "poor". Regarding self-rated health, more ethnic minorities (15.7\%) than Han Chinese (13.4\%) rated their health status as poor. The majority of respondents were married or had partners. Only $9.9 \%$ had a college/university degree. Ethnic minorities were almost twice as likely as Han Chinese to be illiterate. Only 16.7\% of ethnic minorities had received a senior high school education or above, and less than half of Han Chinese had completed senior high school. The number of ethnic minorities who had a college/university degree was only half that of Han Chinese. More than half (56.4\%) of the respondents reported a lower-middle or lower social status. A total of $21.9 \%$ of ethnic minorities and $31.4 \%$ of Han Chinese ranked themselves as being at the bottom of society, while $51.1 \%$ ethnic minorities and $40.8 \%$ of Han Chinese ranked themselves at the middle level of society or above. Overall, ethnic minorities rated their social status higher than did the Han Chinese. Nearly half $(50.50 \%)$ of respondents never participated in any physical exercise, 
Table 2 Sample Characteristics $(n=10,819)$

\begin{tabular}{|c|c|c|c|c|c|c|c|c|}
\hline & & \multicolumn{4}{|c|}{ Ethnicity } & \multirow{2}{*}{\multicolumn{2}{|c|}{ Whole sample }} & \multirow[t]{3}{*}{$P$} \\
\hline & & \multicolumn{2}{|c|}{ Ethnic minority } & \multicolumn{2}{|c|}{ Han Chinese } & & & \\
\hline & & No & N \%. & No & $\mathrm{N} \%$ & No & $\mathrm{N} \%$ & \\
\hline \multirow[t]{2}{*}{ Self-rated Health } & Poor health & 466 & $15.7 \%$ & 1054 & $13.4 \%$ & 1520 & $14.0 \%$ & 0.002 \\
\hline & Good health & 2496 & $84.3 \%$ & 6803 & $86.6 \%$ & 9299 & $86.0 \%$ & \\
\hline \multirow[t]{3}{*}{ Age } & Young & 1421 & $48.0 \%$ & 2934 & $37.3 \%$ & 4355 & $40.3 \%$ & 0.000 \\
\hline & Middle aged & 1336 & $45.1 \%$ & 4020 & $51.2 \%$ & 5356 & $49.5 \%$ & \\
\hline & Old & 205 & $6.9 \%$ & 903 & $11.5 \%$ & 1108 & $10.2 \%$ & \\
\hline \multirow[t]{2}{*}{ Gender } & Female & 1333 & $45.0 \%$ & 4004 & $51.0 \%$ & 5337 & $49.3 \%$ & 0.000 \\
\hline & Male & 1629 & $55.0 \%$ & 3853 & $49.0 \%$ & 5482 & $50.7 \%$ & \\
\hline \multirow[t]{2}{*}{ Marital Status } & Non-partnered & 538 & $18.2 \%$ & 1424 & $18.1 \%$ & 1962 & $18.1 \%$ & 0.962 \\
\hline & Partnered & 2424 & $81.8 \%$ & 6433 & $81.9 \%$ & 8857 & $81.9 \%$ & \\
\hline \multirow[t]{5}{*}{ Education } & Illiterate & 847 & $28.6 \%$ & 916 & $11.7 \%$ & 1763 & $16.3 \%$ & 0.000 \\
\hline & Primary school & 902 & $30.5 \%$ & 1891 & $24.1 \%$ & 2793 & $25.8 \%$ & \\
\hline & Middle school & 717 & $24.2 \%$ & 2505 & $31.9 \%$ & 3222 & $29.8 \%$ & \\
\hline & Senior high school & 324 & $10.9 \%$ & 1646 & $20.9 \%$ & 1970 & $18.2 \%$ & \\
\hline & College/university or above & 172 & $5.8 \%$ & 899 & $11.4 \%$ & 1071 & $9.9 \%$ & \\
\hline \multirow[t]{5}{*}{ Subjective Social Status (SSS) } & Lower & 648 & $21.9 \%$ & 2466 & $31.4 \%$ & 3114 & $28.8 \%$ & 0.000 \\
\hline & Lower-middle & 798 & $26.9 \%$ & 2186 & $27.8 \%$ & 2984 & $27.6 \%$ & \\
\hline & Middle & 1307 & $44.1 \%$ & 2869 & $36.5 \%$ & 4176 & $38.6 \%$ & \\
\hline & Upper-middle & 185 & $6.2 \%$ & 304 & $3.9 \%$ & 489 & $4.5 \%$ & \\
\hline & Upper & 24 & $.8 \%$ & 32 & $.4 \%$ & 56 & $0.5 \%$ & \\
\hline \multirow[t]{2}{*}{ Smoking Status } & Current smoker & 2056 & $69.4 \%$ & 5070 & $64.5 \%$ & 7126 & $65.9 \%$ & 0.000 \\
\hline & Non-smoker & 906 & $30.6 \%$ & 2787 & $35.5 \%$ & 3693 & $34.1 \%$ & \\
\hline \multirow[t]{4}{*}{ Alcohol Consumption } & High-risk drinker & 214 & $7.2 \%$ & 679 & $8.6 \%$ & 893 & $8.3 \%$ & 0.000 \\
\hline & Moderate-risk drinker & 360 & $12.2 \%$ & 1062 & $13.5 \%$ & 1422 & $13.1 \%$ & \\
\hline & Low-risk drinker & 420 & $14.2 \%$ & 1535 & $19.5 \%$ & 1955 & $18.1 \%$ & \\
\hline & Non-drinker & 1968 & $66.4 \%$ & 4581 & $58.3 \%$ & 6549 & $60.5 \%$ & \\
\hline \multirow[t]{5}{*}{ Physical Exercise } & Regularly/every day & 476 & $16.1 \%$ & 2029 & $25.8 \%$ & 2505 & $23.2 \%$ & 0.000 \\
\hline & Several times a week & 208 & $7.0 \%$ & 891 & $11.3 \%$ & 1099 & $10.2 \%$ & \\
\hline & Several times a month & 181 & $6.1 \%$ & 662 & $8.4 \%$ & 843 & $7.8 \%$ & \\
\hline & Once a month or less & 240 & $8.1 \%$ & 673 & $8.6 \%$ & 913 & $8.4 \%$ & \\
\hline & Never & 1857 & $62.7 \%$ & 3602 & $45.8 \%$ & 5459 & $50.5 \%$ & \\
\hline \multirow[t]{2}{*}{ Health Problems } & Person with chronic disease & 918 & $31.0 \%$ & 2482 & $31.6 \%$ & 3400 & $31.4 \%$ & 0.551 \\
\hline & Non-sufferer & 2044 & $69.0 \%$ & 5375 & $68.4 \%$ & 7419 & $68.6 \%$ & \\
\hline
\end{tabular}

such as playing ball, doing Tai Chi, or practising Chinese martial arts. A total of $62.7 \%$ of ethnic minorities and $45.8 \%$ of Han Chinese never participated in any physical exercise. More women (20.3\%) than men (12.4\%) were illiterate. Regarding healthy behaviour, only $4 \%$ of women currently smoked, while $63.5 \%$ of men smoked. Additionally, $14.9 \%$ of men reported high-risk alcohol consumption, which was 10 times the percentage of women who reported being high-risk drinkers (1.4\%). In terms of health problems, more women (34.6\%) than men (28.3\%) had chronic disease.
Ethnic disparities in self-rated health

In Table 3, we show the percentage of respondents reporting poor or good health by ethnicity. A comparison of the sociodemographic characteristics of ethnic minorities and Han Chinese revealed that over one-third (39.5\%) of elderly ethnic minorities reported their health to be poor, and $7.9 \%$ of young ethnic minorities reported poor health. Meanwhile, $29.6 \%$ of elderly Han Chinese reported their health to be poor, while only $3.9 \%$ of young Han Chinese reported poor health. There were obvious statistically significant ethnic disparities between 
Table 3 Self-rated Health Status by Ethnicity (Minzu)

\begin{tabular}{|c|c|c|c|c|c|c|}
\hline & Ethnic minor & & & Han Chinese & & \\
\hline & Poor health & Good health & $P$ & Poor health & Good health & $P$ \\
\hline Age & & & .000 & & & .000 \\
\hline Young & $7.9 \%$ & $92.1 \%$ & & $3.9 \%$ & $96.1 \%$ & \\
\hline Middle aged & $20.4 \%$ & $79.6 \%$ & & $16.8 \%$ & $83.2 \%$ & \\
\hline Old & $39.5 \%$ & $60.5 \%$ & & $29.6 \%$ & $70.4 \%$ & \\
\hline Gender & & & .000 & & & .001 \\
\hline Women & $18.8 \%$ & $81.2 \%$ & & $14.7 \%$ & $85.3 \%$ & \\
\hline Men & $13.3 \%$ & $86.7 \%$ & & $12.1 \%$ & $87.9 \%$ & \\
\hline Marital Status & & & .060 & & & .865 \\
\hline Non-partnered & $18.4 \%$ & $81.6 \%$ & & $13.6 \%$ & $86.4 \%$ & \\
\hline Partnered & $15.1 \%$ & $84.9 \%$ & & $13.4 \%$ & $86.6 \%$ & \\
\hline Education & & & .000 & & & .000 \\
\hline Illiterate & $25.5 \%$ & $74.5 \%$ & & $32.1 \%$ & $67.9 \%$ & \\
\hline Primary school & $17.3 \%$ & $82.7 \%$ & & $19.6 \%$ & $80.4 \%$ & \\
\hline Middle school & $7.3 \%$ & $92.7 \%$ & & $10.5 \%$ & $89.5 \%$ & \\
\hline Senior high school & $9.9 \%$ & $90.1 \%$ & & $6.1 \%$ & $93.9 \%$ & \\
\hline College/university or above & $5.8 \%$ & $94.2 \%$ & & $2.9 \%$ & $97.1 \%$ & \\
\hline SSS & & & .000 & & & .000 \\
\hline Lower & $25.3 \%$ & $74.7 \%$ & & $21.0 \%$ & $79.0 \%$ & \\
\hline Lower-middle & $19.4 \%$ & $80.6 \%$ & & $11.9 \%$ & $88.1 \%$ & \\
\hline Middle & $10.0 \%$ & $90.0 \%$ & & $8.4 \%$ & $91.6 \%$ & \\
\hline Upper-middle & $8.6 \%$ & $91.4 \%$ & & $8.2 \%$ & $91.8 \%$ & \\
\hline Upper & $0.0 \%$ & $100.0 \%$ & & $21.9 \%$ & $78.1 \%$ & \\
\hline Smoking & & & .001 & & & .192 \\
\hline Current smoker & $12.5 \%$ & $87.5 \%$ & & $12.7 \%$ & $87.3 \%$ & \\
\hline Non-smoker & $17.2 \%$ & $82.8 \%$ & & $13.8 \%$ & $86.2 \%$ & \\
\hline Alcohol & & & .000 & & & .000 \\
\hline High-risk drinker & $9.3 \%$ & $90.7 \%$ & & $8.2 \%$ & $91.8 \%$ & \\
\hline Moderate-risk drinker & $9.2 \%$ & $90.8 \%$ & & $5.8 \%$ & $94.2 \%$ & \\
\hline Low-risk drinker & $9.5 \%$ & $90.5 \%$ & & $9.2 \%$ & $90.8 \%$ & \\
\hline Non-drinker & $19.0 \%$ & $81.0 \%$ & & $17.4 \%$ & $82.6 \%$ & \\
\hline Physical Exercise & & & .000 & & & .000 \\
\hline Regularly/every day & $14.5 \%$ & $85.5 \%$ & & $15.4 \%$ & $84.6 \%$ & \\
\hline Several times a week & $6.2 \%$ & $93.8 \%$ & & $7.7 \%$ & $92.3 \%$ & \\
\hline Several times a month & $11.0 \%$ & $89.0 \%$ & & $5.6 \%$ & $94.4 \%$ & \\
\hline Once a month or less & $12.1 \%$ & $87.9 \%$ & & $7.7 \%$ & $92.3 \%$ & \\
\hline Never & $18.0 \%$ & $82.0 \%$ & & $16.2 \%$ & $83.8 \%$ & \\
\hline Health Problems & & & .000 & & & .000 \\
\hline Person with chronic disease & $41.5 \%$ & $58.5 \%$ & & $36.0 \%$ & $64.0 \%$ & \\
\hline Non-sufferer & $4.2 \%$ & $95.8 \%$ & & $3.0 \%$ & $97.0 \%$ & \\
\hline
\end{tabular}

Han Chinese and ethnic minorities among the young and the elderly. Han Chinese men were the least likely to report poor health (12.1\%), while ethnic minority women were the most likely to report poor health
(18.8\%). Regardless of ethnic differences, in general, women were more likely than men to rate their health status as poor. A total of $18.4 \%$ of non-partnered ethnic minorities reported poor health, which was slightly 
higher than the percentage of partnered ethnic minorities who reported poor health (15.1\%). However, such differences in marital status did not exist among Han Chinese.

More illiterate Han Chinese (32.1\%) reported poor health than illiterate ethnic minorities (25.5\%). We observed that with the increase of years in school, the percentage of reporting poor health sharply decreased by nearly 30 and $20 \%$ for Han Chinese and ethnic minorities, respectively. Respondents who ranked their subjective social status (SSS) as middle or upper-middle class basically showed the same trend in self-rated health among either Han Chinese or ethnic minorities.

For ethnic minorities, there was not much difference in the percentage of respondents who reported good health among the high-risk (90.7\%), moderate-risk (90.8\%) and low -risk (90.5\%) drinkers. However, for Han Chinese, $94.2 \%$ of moderate-risk drinkers reported good health, which was slightly higher than the percentages of high-risk (91.8\%) and low-risk (90.8\%) drinkers. Among current smokers, ethnic minorities and Han Chinese presented similar patterns of self-rated health. Ethnic minorities who had chronic disease (41.5\%) were more likely to report poor health than their Han Chinese counterparts (36\%).

\section{Logistic regression model of self-rated health}

The primary aim of this study was to estimate the association between ethnic disparity and self-rated health. Therefore, we examined disparities in self-rated health independent of ethnicity (Model 1), sociodemographic factors (Model 2), socioeconomic status (Model 3), health behaviour factors (Model 4) and health problem factors (Model 5) (Table 4). In general, all models presented similar findings (Table 3) of a significant difference in self-rated health between ethnic minority and Han Chinese. Our primary hypothesis that ethnic minorities' self-rated health would be significantly worse than that of Han Chinese, who were expected to have better social economic status (SES), was statistically supported $(\mathrm{P}<0.001$ in Model 3). We found that sociodemographic factors explained a large part of the difference between ethnic minority and Han Chinese self-rated health. Compared to Han Chinese, ethnic minorities were more likely to report poor health, and the likelihood increased by $22.8 \%$ between Model 1 and Model 2. The self-rated health status of young and middle-aged people was better than that of older people. Hypothesis 2 was statistically supported. The correlation between female gender and self-rated health was strong in Model 2 and Model 3 . However, this correlation disappeared when health behaviour and health problem factors were introduced into Model 4 and Model 5.
Non-partnered patients were more likely to report poor health, which was consistent with hypothesis 4 . Among the education groups, being illiterate and having a primary school and middle school education level consistently had significant effects in Model 3, Model 4 and Model 5, indicating that self-rated health was correlated with educational level. An increase in years in school decreased the likelihood of reporting poor health, and hypothesis 5 was statistically supported. For SSS, we observed a consistent pattern in Model 3, Model 4 and Model 5. In each model, ethnic minorities who ranked themselves as lower or lower-middle class were more likely to report poor health than those who ranked themselves as middle class or higher, but this difference was never statistically significant. That is, there was no statistically significant difference in the relationship between SSS and self-rated health by ethnicity.

The results of Model 4 still showed an ethnic difference between Han Chinese and ethnic minorities in selfrated health. The health behaviour factors explained the difference in self-rated health between Han Chinese and ethnic minorities. However, the difference was not as large in Model 4 as it was in Model 1. For alcohol consumption, we observed a consistent pattern in Model 4 and Model 5, and there was a strong correlation between alcohol consumption and self-rated health. Among Han Chinese, those who drank were less likely to report poor health, which was opposite to hypothesis 8 . For smoking, there was no statistically significant difference in the relationship between smoking and self-rated health by ethnicity. Regarding physical exercise, we observed that those who exercised were less likely to report poor health, so hypothesis 9 was statistically supported. There was a statistically significant ethnic difference in the relationship between physical exercise and self-rated health.

In terms of health problem factors, an ethnic disparity in self-rated health existed. People who had chronic disease were more likely to report poor health, which was consistent with hypothesis 10 .

\section{Discussion}

The primary aim of this study was to estimate the association between ethnic disparity and self-rated health, and the secondary aim was to identify the influencing factors that might bring about health inequality in western China. Our results showed a positive association between ethnic disparities and self-rated health. Although the magnitude of this association slightly varied when more control variables were stepwise introduced into the models (Model 2 to Model 5), there were always significant ethnic difference from Model 1 to Model 5. We found that age, marital status, education level, alcohol consumption, physical exercise and chronic disease all had a consistent effect on the relationship between 
Table 4 Self-rated Health Logistic Regression Models

\begin{tabular}{|c|c|c|c|c|c|c|c|c|c|c|}
\hline & \multicolumn{2}{|l|}{ Model 1} & \multicolumn{2}{|l|}{ Model 2} & \multicolumn{2}{|l|}{ Model 3} & \multicolumn{2}{|l|}{ Model 4} & \multicolumn{2}{|l|}{ Model 5} \\
\hline & $\beta$ & SE & $B$ & SE & $B$ & SE & $\beta$ & SE & $B$ & SE \\
\hline Ethnic minority & $-.187^{* *}$ & .060 & $-.415^{* * *}$ & .064 & $-.243^{* * *}$ & .068 & $-.193^{* *}$ & .070 & $-.222^{* *}$ & .077 \\
\hline \multicolumn{11}{|l|}{ Age } \\
\hline Young & & & $2.257^{* * *}$ & .096 & $1.816^{* * *}$ & .102 & $1.761^{* * *}$ & .105 & $.981^{* * *}$ & .115 \\
\hline Middle aged & & & $.771^{* * *}$ & .076 & $.590^{* * *}$ & .081 & $.547^{* * *}$ & .082 & $.238^{* *}$ & .090 \\
\hline Women & & & $-.412^{* * *}$ & .058 & $-.287^{* * *}$ & .061 & -.091 & .080 & .035 & .088 \\
\hline Non-partnered & & & $-.267^{* *}$ & .077 & $-.190^{*}$ & .080 & $-.234^{* *}$ & .081 & $-.244^{* *}$ & .089 \\
\hline \multicolumn{11}{|l|}{ Education } \\
\hline Illiterate & & & & & $-1.768^{* * *}$ & .184 & $-1.523^{* * *}$ & .187 & $-1.334^{* * *}$ & .197 \\
\hline Primary school & & & & & $-1.344^{* * *}$ & .181 & $-1.145^{* * *}$ & .184 & $-1.015^{* * *}$ & .193 \\
\hline Middle school & & & & & $-.779^{* * *}$ & .183 & $-.605^{* *}$ & .185 & $-.574^{* *}$ & .195 \\
\hline Senior high school & & & & & -.373 & .196 & -.260 & .197 & -.242 & .207 \\
\hline \multicolumn{11}{|l|}{ SSS } \\
\hline Lower & & & & & -.488 & .425 & -.513 & .431 & -.291 & .486 \\
\hline Lower-middle & & & & & -.006 & .426 & -.061 & .432 & .204 & .487 \\
\hline Middle & & & & & .489 & .426 & .448 & .432 & .572 & .487 \\
\hline Upper-middle & & & & & .567 & .456 & .508 & .461 & .611 & .517 \\
\hline Current smoker & & & & & & & -.099 & .086 & -.077 & .095 \\
\hline \multicolumn{11}{|l|}{ Alcohol } \\
\hline High-risk drinker & & & & & & & $.831^{* * *}$ & .137 & $.499^{* *}$ & .149 \\
\hline Moderate-risk drinker & & & & & & & $.817^{* * *}$ & .121 & $.569^{* * *}$ & .131 \\
\hline Low-risk drinker & & & & & & & $.485^{* * *}$ & .093 & $.407^{* * *}$ & .101 \\
\hline \multicolumn{11}{|l|}{ Physical exercise } \\
\hline Regularly/every day & & & & & & & .125 & .074 & $.214^{* *}$ & .081 \\
\hline Several times a week & & & & & & & $.375^{* *}$ & .129 & $.373^{* *}$ & .140 \\
\hline Several times a month & & & & & & & $.416^{* *}$ & .152 & $.405^{*}$ & .164 \\
\hline Once a month or less & & & & & & & .196 & .131 & .149 & .143 \\
\hline Person with chronic disease & & & & & & & & & $-2.498^{* * *}$ & .077 \\
\hline Intercept & $1.865^{* * *}$ & .033 & $1.117^{* * *}$ & .075 & $2.287^{* * *}$ & .460 & $1.809^{* * *}$ & .472 & $3.266^{* * *}$ & .527 \\
\hline Nagelkerke $R^{2}$ & .002 & & .118 & & .195 & & .210 & & .397 & \\
\hline
\end{tabular}

Significance codes: ${ }^{*} P<0.05,{ }^{* *} P<0.01,{ }^{* * *} P<0.001$. Reference categories: 1 -Older; $2-$ Man; 3 -Han Chinese; 4-Upper; 5-College/university or above; 6-Nondrinkers; 7-Never; 8-Non sufferer; 9-Partnered; 10-Non-smoker

ethnic differences and self-rated health. The self-rated health appeared to be independent of subjective social status (SSS) and smoking behaviour; these findings were not in line with previous studies [80-83].

It is not surprising that the elderly are more likely to suffer from and report a poor health status. China currently has a rapidly ageing society, and the demographic structures and health status of ethnic minorities observed in the CSSC2010 database might be exacerbated over time. With rapid urbanization, a growing number of ethnic minorities have experienced dramatic changes in their ways of life. For some ethnic minorities, a seminomadic way of life has become only a memory, as they have moved into multi-storied houses in concentrated community. Such lifestyle changes raise questions, such as whether changes in dietary patterns affect ethnic minorities' health and increase the risk of obesity or other diseases. Therefore, it is of great practical significance to conduct a follow-up survey to obtain an updated view of the disparity between ethnic minorities and Han Chinese.

In previous studies, socioeconomic status (SES) was identified as a determinant of health inequality [20] [23]. The results of the present study showed that subjective social status (SSS) had no significant effects in Models 3 to 5 . Therefore, strictly speaking, SES could not be the determining factor of self-rated health in our study. A possible explanation is that different measurements of 
SES might affect the results; for example, income, occupation, family-owned luxury goods, or bank deposits are some variables that have often been used to measure SES [8].

The World Health Organization showed that chronic diseases such as heart disease, stroke, cancer, chronic respiratory disease and diabetes were by far the world's leading causes of morbidity and mortality $[84,85]$. The incidence of chronic disease in China has been on the rise, and there are obvious differences between urban and rural areas. Diseases such as high blood pressure, coronary heart disease, and diabetes and disc disease are higher among urban residents, while gastroenteritis and other motor system diseases are more prevalent among rural residents [19] [86]. Ethnic minorities often inhabit economically underdeveloped and geographically remote areas, and medical and health resources are relatively scarce. A lack of chronic disease prevention knowledge could also impact ethnic minorities' health status. In addition, ethnic differences have been observed in cognition of illness or disease. A survey of ethnic minorities in Guizhou Province in southwestern China showed that only $38.5 \%$ of people fully agreed that regular health checks were necessary and good for health. If they became sick, many of them would not stop working or ask for treatment until they could no longer get out of bed [87].

Cultural traditions can impact individuals' health behaviour. For Han Chinese, the percentage of moderaterisk drinkers was higher than that of high-risk drinkers and low-risk drinkers, which might be due to the unique thinking related to the Doctrine of the Mean (Zhongyong) of Confucianism in Chinese culture. The Doctrine of the Mean emphasizes moderation and suggests that going beyond is as wrong as falling short. It is believed that drinking a little every day is good for health. The adage "no gift but wine" embodies the hospitality of ethnic minorities. Wine is a necessity on important occasions, such as religious ceremonies, wedding or burial ceremonies, and for hosting guests.

This study was designed to establish a baseline association between ethnic disparities and self-rated health and its influencing factors. Future research should further explore the process through which ethnic minorities are more likely to experience poor health outcomes than non-minorities. Future research should also focus more on the spatial distribution characteristics of ethnic minorities and their impact on ethnic minority health outcomes. In addition, future research should focus on the cultural uniqueness and acculturation of ethnic minorities related to perceptions of illness, subjective social status, and health status. Of course, one limitation of our research is that the imbalance in the independent variables for the secondary study aims between Han
Chinese and ethnic minorities, except for the variables of marital status and health problems, may have led to bias in the estimation of causal effects. Another limitation is that the data used in this study were collected in 2010, so we acknowledge that our findings are not perfectly valid in the current context. Nonetheless, we attempted a first step towards the identification of the existing state of racial disparities in health outcomes, which is a step that we hope will be followed by other studies in the future.

\section{Conclusion}

This study demonstrated that ethnic disparities in selfrated health did exist in western China and that ethnic minorities who were elderly, were non-partnered, had an educational level lower than middle school, and had chronic disease had higher odds of poor self-rated health. A novel finding was that self-rated health appeared to be independent of subjective social status (SSS) and smoking behaviour; these findings were not in line with previous studies. There was no statistically significant ethnic difference in the relationship between SSS and self-rated health or for the relationship between smoking behaviour and self-rated health. Whatever the reasons might be, the inconsistent findings suggest that additional future studies are needed to explore the potential ethnic differences in the relationship of self-rated health with SSS and with smoking behaviour. Few studies have examined ethnic disparities in self-rated health in western China, and this study added to the extant research by providing an essential understanding of ethnic minorities' health status and influencing factors. An accurate understanding of ethnic minorities' health status in western China should not be overlooked in the achievement of the Health China 2030 plan and the 2030 sustainable development goals.

\section{Abbreviations}

CSSC: China Survey of Social Change; SSS: Subjective Social Status;

SES: Socioeconomic Status; PRC: People's Republic of China; WHO: World Health Organization

\section{Acknowledgements}

The authors would like to thank Wen-li Qiang, Xing-liang Kou and Jian Fu for their insightful and kind comments on this study.

\section{Authors' contributions}

YW and XC conceived and designed the study; YW, WC, and ZZ contributed to data collection, analysis and interpretation; YW and ZZ wrote the initial draft of manuscript; XC and WC supervised of the manuscript. YZ and ZJ contributed to interpretation and critically reviewed the manuscript. All authors have read and approved the manuscript.

\section{Authors information}

Affiliations:

College of Earth and Environmental Sciences, Lanzhou University, Lanzhou, 730000, People's Republic of China.

Yueju Wang, Xingpeng Chen, Zilong Zhang \& Zhuo Jia. Research Center for Circular Economy in Western China, Lanzhou University, Lanzhou 730000, People's Republic of China. 
Yueju Wang, Xingpeng Chen \& Zilong Zhang.

Philosophy and Sociology School of Lanzhou University, Lanzhou, 730000 People's Republic of China.

Wenjiang Chen \& Yaping Zhou.

Key Laboratory of Western China's Environmental Systems (Ministry of Education), Lanzhou University, Lanzhou, 730000, People's Republic of China. Xingpeng Chen \& Zilong Zhang.

\section{Funding}

This research was funded by the Natural Science Foundation of China (Grant number: 41561110$)$, the Key Project of the National Social Science Foundation of China "Sociology theory, method, and topics on western China" (Grant number: 14ASH003), and the Fundamental Research Funds for the Central Universities (Grant number: Izujbky-2018-137) for data collection and analysis. These funders had no role in study design, data interpretation and manuscript writing.

\section{Availability of data and materials}

The data that support the findings of this study are available from Sociology IESSR, Xi'an Jiao tong University, but restrictions apply on the availability of these data, which were used under license for the current study and are thus not publicly available. However, the data are available from the authors upon reasonable request and with the permission of Sociology IESSR, Xi'an Jiao tong University.

\section{Ethics approval and consent to participate}

Not applicable.

\section{Consent for publication}

Not applicable.

\section{Competing interests}

The authors declare that they have no competing interests.

\section{Author details}

${ }^{1}$ College of Earth and Environmental Sciences, Lanzhou University, Lanzhou 730000, China. ${ }^{2}$ Research Center for Circular Economy in Western China, Lanzhou University, Lanzhou 730000, China. ${ }^{3}$ Philosophy and Sociology School of Lanzhou University, Lanzhou 730000, China. ${ }^{4}$ Key Laboratory of Western China's Environmental Systems (Ministry of Education), Lanzhou University, Lanzhou 730000, China.

\section{Received: 17 September 2019 Accepted: 24 March 2020}

\section{Published online: 07 May 2020}

\section{References}

1. Thorpe KE, Howard DH, Galactionova K. Differences in disease prevalence as a source of the U.S.-European health care spending gap. Health Affair. (Millwood). 2007;26:678-86.

2. Ho JY. Mortality under age 50 accounts for much of the fact that US life expectancy lags that of other high-income countries. Health Affair (Millwood). 2013;32:459-67.

3. Kearns $\mathrm{R}$, Moewaka-Barnes $\mathrm{H}, \mathrm{McCreanor}$ T. Placing racism in public health: a perspective from Aotearoa/New Zealand. GeoJ. 2009:74:123-9.

4. Heckler M. Report of the secretary's task force on black minority health. US Dep Health Hum Serv. 1985.

5. Xiong Y Study of ethnic minorities' mortality in China. Chinese J Popul Sci. 1987, 2, 59-65(In Chinese).

6. Qian JM, Zhang Q. An analysis of mortality of Chinese minorities. Popul Res 1990, 1, 15-18(In Chinese).

7. National Center for Health Statistics (US). Health, United States, 2015: with special feature on racial and ethnic health disparities. (2016).

8. Frieden TR. CDC health disparities and inequalities report-United States, 2013. Foreword MMWR. 2013;62(3):1-2.

9. Guo W. The population trend of the ethnic groups in contemporary China: 2000-2010. Popul J. 2014, 36, 13-21(In Chinese).

10. Acheson D. Independent inquiry into inequalities in health: report. HM Stationery Off. 1998

11. Adelson N. The embodiment of inequity: health disparities in aboriginal Canada. Canadian J Public Health. 2005;96(Suppl.2):S45-61.
12. Cooper RS. A case study in the use of race and ethnicity in public health surveillance. Public Health Rep. 1994;109:46-52.

13. Fullilove MT. Comment: abandoning "race" as a variable in public health research_an idea whose time has come. Am J Public Health. 1998:88:1297-8.

14. Ford CL, Airhihenbuwa CO. The public health critical race methodology: praxis for antiracism research. Soc Sci Med. 2010;71(8):1390-8.

15. White K. The sustaining relevance of W.E.B.DU BOIS to health disparities research. Du Bois Rev Soc Sci Res Race. 2011;8(1):285-93.

16. Link BG, Phelan J. Social conditions as fundamental causes of disease. J Health Soc Behav. 1995;(Extra Issue):80-94.

17. Li RB, Wang WY, Tan JA, Li HR. The health index of Chinese and its regional deference. Human Geogr. 2004, 19(3), 64-68(In Chinese).

18. Liu M, Zhang Q, Lu M, Kwon CS, Quan H. Rural and urban disparity in health services utilization in China. Med Care. 2007:45(8):767-74.

19. Xie E Income-related inequality of health and health care utilization. Econ Res. 2009, 92-105(In Chinese).

20. Qi LS. Income, income inequality and health: the impacts of rural-urban gap and occupational status. Econ Res. 2006, 11, 16-26(In Chinese).

21. Sun QA, Li XJ. Self-perceived health of residents and social stratification: An empirical research based on CGSS 2008. Stat Inf Forum. 2013, 28, 78-83(In Chinese).

22. Liu LH, Tang JX. Research of socioeconomic status effects health disparity Chinese Health Econ. 2004, 23 (6), 40-42(In Chinese).

23. Wang FQ. Socioeconomic status, lifestyle and health inequality. Society 2012, 2,125-143(In Chinese)

24. Jiao KS. Health inequalities of different socio-economic status and its influencing factors. Sociological Studies. 2014, 29, 24-46(In Chinese).

25. Qian JM, Zhang Q. A study of the mortality rate of ethnic minorities in China. Population Research. 1990, 1, 15-18(In Chinese).

26. Chen XF, Zhang JY, Zhang Q. An analysis on the trend of infant mortality rate of Chinese minorities. Modern Preventive Medicine. 2006, 33(12), 2231 2239(In Chinese).

27. Phelan JC, Link BG, Tehranifar P. Social conditions as fundamental causes of health inequalities theory, evidence, and policy implications. Health Soc Behav. 2010;51:\$28-40

28. Kawachi I, Kennedy BP. Income inequality and health: pathways and mechanisms. Health Serv Res. 1999:34:215-27.

29. Mellor JM, Milyo JD. Income inequality and health. J Policy Anal Manage. 2001;20:151-5.

30. Bleich SN, Jarlenski MP, Bell CN, LaVeist TA. Health inequalities: trends, progress, and policy. Annu Rev Public Health. 2012;33:7-40.

31. Blom N, Huijts T, Kraaykamp G. Ethnic health inequalities in Europe. The moderating and amplifying role of healthcare system characteristics. Soc Sci Med. 2016;158:43-51.

32. LaVeist TA, Lebrun LA. Cross-country comparisons of racial/ethnic inequalities in health. J Epidemiol Commun Health. 2010;64:7.

33. Carter L. Using data more effectively to describe ethnic health inequalities in the UK. Eur J Public Health. 2018;28(suppl_1).

34. Nazroo JY. The structuring of ethnic inequalities in health: economic position, racial discrimination, and racism. Am J Public Health. 2003;93:277-84.

35. Read UM. Health inequalities: from ethnicity to diversity. Ethn Health. 2014; 19:119-21.

36. Mindell JS, Knott CS, Fat LN, Roth MA, Manor O, Soskolne V, Daoud N. Explanatory factors for health inequalities across different ethnic and gender groups: data from a national survey in England. J Epidemiol Commun Health. 2014;68:1133-44.

37. Mackenbach JP, Kunst AE, Cavelaars AE, Groenhof F, Geurts JJ. EU working group on socioeconomic inequalities in health socioeconomic inequalities in morbidity and mortality in Western Europe. The Lancet. 1997:349(16551659):38.

38. Marmot MG, Stansfeld S, Patel C, North F, Head J, White I, Brunner E, Feeney A, Smith GD. Health inequalities among British civil servants: the Whitehall II study. Lancet. 1991;337:1387-93.

39. Hayward MD, Miles TP, Crimmins EM, Yang Y. The significance of socioeconomic status in explaining the racial gap in chronic health conditions. Am Sociol Rev. 2000:65:910-30.

40. Williams DR, Collins C. US socioeconomic and racial differences in health: patterns and explanations. Annu Rev Sociol. 1995:21:349-86.

41. Winkleby MA, Jatulis DE, Frank E, Fortmann SP. Socioeconomic status and health: how education, income, and occupation contribute to risk factors for cardiovascular disease. Am J Public Health. 1992;82:816-20. 
42. Ostrove MJ, Adler E. Nancy. Socioeconomic status and health. Am Econ Rev. 1998;49:15-24.

43. Tracy M, Zimmerman FJ, Galea S, McCauley E, Vander SA. What explains the relation between family poverty and childhood depressive symptoms? J Psychiatr Res. 2008;42:1163-75.

44. Lillard DR, Burkhauser RV, Hahn MH, Wilkins R. Does early-life income inequality predict self-reported health in later life? Evidence from the United States. Soc Sci Med. 2015;128:347-55.

45. Preston $\mathrm{SH}$. The changing relation between mortality and level of economic development. Popul Stud. 1975;29(2):231-48.

46. Rodgers GB. Income and inequality as determinants of mortality: an international cross-section analysis. Popul Stud. 1979;33:343-51.

47. Gravelle $\mathrm{H}$. How much of the relation between population mortality and unequal distribution of income is a statistical artefact? Br Med J. 1998:31682.

48. Wilkinson RG. Commentary: income inequality summarizes the health burden on individual relative deprivation. Br Med J. 1997:314:1727-8.

49. Wolfson MC, Kaplan G, Lynch J, Ross N, Backlund E. Relation between income inequality and mortality: empirical demonstration. Br Med J. 1999: 319-953.

50. Cassel J. The contribution of the social environment to host resistance: the fourth Wade Hampton frost lecture. Am J Epidemiol. 1976;104(2):107-23.

51. Cobb S. Social support as a moderator of life stress. Psychosom Med. 1976; 38(5):300-14.

52. Berkman LF, Syme SL. Social networks, host-resistance, and mortality: a nineyear follow-up study of alameda county residents. Am J Epidemiol. 1979; 109(2):186-204.

53. Blazer D. Social support and mortality in an elderly community population. Am J Epidemiol. 1982;115:684-94

54. House JS, Robbins C, Metzner HL. The association of social relationships and activities with mortality: prospective evidence from the Tecumseh community health study. Am J Epidemiol. 1982;116:123-40.

55. Young M, Benjamin B, Wallis C. The mortality of widowers. Lancet. 1963;282: 454-7.

56. Black DR, Gleser LJ, Kooyers KJ. A meta-analytic evaluation of couples' weight-loss programs. Health Psychol. 1990;9(3):330-47.

57. Christakis NA, Fowler $\mathrm{JH}$. The spread of obesity in a large social network over 32 years. N Engl J Med. 2007;357(4):370-9.

58. Entwisle B, Faust $K$, Rindfuss RR, Kaneda T. Networks and contexts: variation in the structure of social ties. Am J Sociol. 2007:112(5):1495-533.

59. Schulz AJ, Williams DR, Israel BA, Lempert LB. Racial and spatial relations as fundamental determinants of health in Detroit. Milbank Q. 2002:80:677-707.

60. Lee L. The current state of public health in China. Annu Rev Public Health. 2004;25:327-39.

61. Li RB, Wang WY, Tan JA. The health index of Chinese and its regional difference. Human Geogr. 2004, 19, 64-68(In Chinese).

62. Tang S, Meng Q, Chen L, Bekedam H, Evans T, Whitehead M. Tackling the challenges to health equity in China. Lancet. 2008:372:1493-501.

63. Liu B, Jiang F, Hu SH. Geographic differences on population's health. Chinese Health Resour. 2006, 9, 12-14(In Chinese).

64. Hu L A demonstration study on the unfair health condition with their income in China. Health Econ Res. 2005, 12, 13-16(In Chinese).

65. Du P An analysis on the health status of the older persons in China. Popul Econ. 2013, 6, 3-9(In Chinese).

66. Poston DL, Jing S. The demographic and socioeconomic composition of China's ethnic minorities. In the population of modern China 1992 (pp. 573600). Springer, Boston, MA

67. Zhang Q, Qian JM. A study on the health condition of Chinese minorities children. Mod Prev Med. 1997, 24(3), 319-321(In Chinese).

68. Tan J Health, environment and development-the theme of contemporary medical geography. Acta Geographica Sinica. 1994, 49(Supplement),710718 (In Chinese).

69. Yang LS, Wang WY, Tan J, Liang T, Dong YS. Overview on the research works in the field of environmental geography and human health. Geogr Res. 2010, 29(9), 1571-1583(In Chinese).

70. Wang WY, Li RB, Tan J. The main fields of study on environment-health and development in 21TH century in China. Prog Geogr. $1997,16(1), 11-14$ (In Chinese).

71. Yang LS, Li HR, Li YH, Wang WY, Tan J. Progress of medical geography and environmental health studies. Prog Geogr. 2010;29(1):31-44 (In Chinese).
72. Bian YJ. The Western China report. Beijing: China Social Science Press; 2013. (In Chinese).

73. Rubin DB. Inference and missing data. Biometrika. 1976;63:581-92.

74. Oftedal S, Kolt GS, Holliday EG, Stamatakis E, Vandelanotte C, Brown WJ, Duncan MJ. Associations of health-behavior patterns, mental health and self-rated health. Prev Med. 2019;118:295-303.

75. Idler EL, Benyamini Y. Self-rated health and mortality: a review of twentyseven community studies. J Health Soc Behav. 1997;38(1):21-37.

76. Qi YQ. Reliability and validity of self-rated general health. Soc Chinese J Sociol/Shehui. 2014;6:196-215.

77. Krause L, Lampert T. Relation between overweight/obesity and self-rated health among adolescents in Germany. Do socio-economic status and type of school have an impact on that relation? Int J Environ Res Public Health. 2015;12:2262-76.

78. Wolff LS, Subramanian SV, Acevedo-Garcia D, Weber D, Kawachi I. Compared to whom? Subjective social status, self-rated health, and referent group sensitivity in a diverse US sample. Soc Sci Med. 2010;70:2019-28.

79. Garza JR, Glenn BA, Mistry RS, Ponce NA, Zimmerman FJ. Subjective social status and self-reported health among US-born and immigrant Latinos. J Immigr Minor Health. 2017;19:108-19.

80. Conry MC, Morgan K, Curry P, McGee H, Harrington J, Ward M, Shelley E. The clustering of health behaviors in Ireland and their relationship with mental health, self-rated health and quality of life. BMC Public Health. 2011; 11:692.

81. Griffin B, Sherman KA, Jones M, Bayl-Smith P. The clustering of health behaviors in older Australians and its association with physical and psychological status, and sociodemographic indicators. Ann Behav Med. 2014;48:205-14.

82. Verger $\mathrm{P}$, Lions $\mathrm{C}$, Ventelou B. Is depression associated with health riskrelated behavior clusters in adults? Eur J Pub Health. 2009;19(6):618-24.

83. Xu SY, Wang NN. Economic status, subjective social status and self-rated health. Stat Res. 2015;32(3):62-8 (In Chinese).

84. World Health Organization. Preventing Chronic Diseases: a vital investment: WHO global report. 2005.

85. Hong YB. Ethnic groups and educational inequalities: an empirical study of the educational attainment of the ethnic minorities in Western China. Chinese J Sociol/Shehui. 2010:2:45-73 (In Chinese).

86. Anayotes D, James N, Elizabeth B, Michael M. Socioeconomic status and health: the role of subjective social status. Soc Sci Med. 2008:67:330-40.

87. Braveman P, Cubbin C, Marchi K, Egerter S, Chavez G. Measuring socioeconomic status position in studies of racial ethnic disparities: maternal and infant health. Public Health Rep. 2001;116:449-63.

\section{Publisher's Note}

Springer Nature remains neutral with regard to jurisdictional claims in published maps and institutional affiliations.
Ready to submit your research? Choose BMC and benefit from:

- fast, convenient online submission

- thorough peer review by experienced researchers in your field

- rapid publication on acceptance

- support for research data, including large and complex data types

- gold Open Access which fosters wider collaboration and increased citations

- maximum visibility for your research: over $100 \mathrm{M}$ website views per year

At $\mathrm{BMC}$, research is always in progress.

Learn more biomedcentral.com/submissions 